\title{
Initial Assessment, Debridement, and Decision Making in the Salvage of Severely Injured Lower Extremity
}

\author{
${ }^{1}$ Department of Plastic Surgery, Ganga Medical Centre and \\ Hospitals, Coimbatore, Tamil Nadu, India
}

S. Raja Sabapathy ${ }^{1}$ Hari Venkatramani ${ }^{1}$ Monusha Mohan ${ }^{1}$

\begin{abstract}
Address for correspondence Raja Sabapathy, MS, MCh(Plast), DNB(Plast), EDHS, Department of Plastic, Hand \& Reconstructive Microsurgery, Ganga Hospital, 313, Mettupalayam Road, Coimbatore, 641 043, India (e-mail: rajahand@gmail.com).
\end{abstract}

Indian J Plast Surg 2019;52:10-16

\begin{abstract}
Keywords

- open fractures

- lower limb

- debridement

- limb salvage scores

An open fracture with extensive skin and soft tissue loss is considered as a severely injured lower extremity. Advances in rapid transport, resuscitation, skeletal fixation, and microsurgical techniques to cover large soft tissue and bone defects have made possible the salvage of these severely injured limbs. Salvage exercise is skill and resource intensive and could take a long time frame. The goal of management is to obtain painless independent weight bearing walking in a time frame and cost that the patient can afford.

Decisions taken and the quality of care provided on day 1 determine the ultimate success. Inappropriate decisions and treatment lead to increased morbidity and secondary amputation. Infection is the commonest complication. Limb salvage scores are helpful to predict salvage and guide the sequence of treatment. Once the decision is taken for salvage, debridement, early skeletal fixation, and soft tissue cover are the key to success.
\end{abstract}

\section{Introduction}

An open fracture of the lower extremity with extensive skin and soft tissue loss is considered to be a severely injured lower extremity. It may be associated with injury to neurovascular structures posing an immediate threat to the survival of the limb.

A century ago, such injuries were life threatening. With the introduction of antibiotics, blood transfusion, early transport to higher centers of medical care, lives were saved but limbs continued to be lost due to infection and the inability to provide soft tissue cover to the fracture sites. Advances in microsurgery and increased collaboration between orthopaedic and plastic surgeons supported by advances in anesthesia made salvage of limbs possible. Saving limbs now has become commonplace, and the challenge is to make the outcomes acceptable and affordable to the patient. The management of severely injured lower extremity has thus passed through the eras of life preservation to limb preservation to functional restoration to the era of aesthetic acceptance.

\section{Challenges in Decision Making on Day 1}

At the time of injury, all patients and their families want reconstruction of the lower extremity and no one prefers amputation. The patient and the family do not really know what they are in for when they accept reconstruction in terms of time frame of treatment and cost and care. ${ }^{1}$ A severely injured lower extremity with bone and soft tissue loss might need up to 18 months of treatment before the patient goes on to independent weight bearing walking (-Fig. 1). It can economically and socially stress the family. So, it becomes the responsibility of the primary care surgeon to help the patient make the right decision by providing them the needed information and putting facts in the right perspective.

Experience gained through treating such injuries over three decades has taught us that the chief determinant of ultimate outcome depends upon the decisions made and the quality of care provided to the patient on day 1 . If there is a compromise in the initial care, there is an increase in
DOI https://doi.org/

10.1055/s-0039-1689741

ISSN 0970-0358.
(C)2019 Association of Plastic Surgeons of India
License terms

(요 (1) $\Theta \circledast$ 

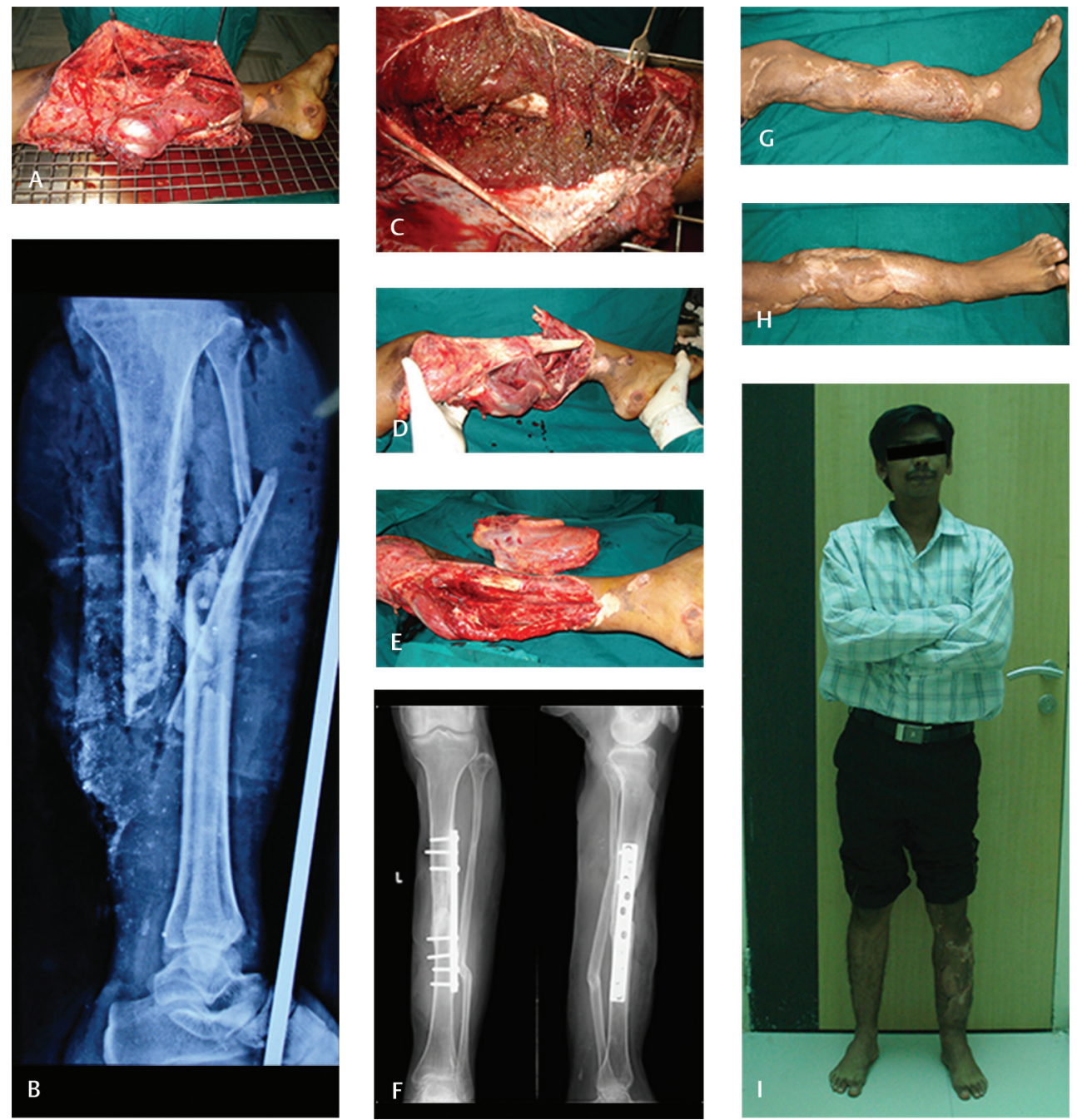

Fig. 1 (A) An open fracture of the leg with soft tissue loss. (B) Radiograph showing the fractures. (C) Extensive contamination of road dust in between the muscle planes, seen well due to the debridement being done under tourniquet. (D) The leg after debridement, free of contaminants, and the fracture ends bereft of periosteum. (E) Initial stabilization with an external fixator and coverage of the exposed bone with free latissimus dorsi flap (external fixator covered by towel). (F) Nonunion at the fracture site treated with plating and bone grafting. (G, $\mathbf{H})$ The end result with fully healed wounds with bone union. (I) Patient achieved painless independent weight bearing walking at 18 months since injury.

the morbidity rate and secondary amputation which the patient and developing economies can ill afford. To help the decision-making process on salvage of the severely injured lower extremity, surgeons attempted to devise scores.

\section{Salvage of Severely Injured Lower Extremity-Value of the Scoring Systems}

Surgeons classified disease conditions with a goal of simplifying the decision-making process in evaluating different options of treatment. Open injuries of the extremities were no exception. The first major classification which has long survived is the Gustilo scoring system published in $1976 .{ }^{2}$ The paper is a combination of a retrospective study of patients from 1955 to 1968 (673 patients) and a prospective study from 1969 to 1973 (352 patients). Based on the findings of the prospective study group, they classified open fractures into three categories
Type I: An open fracture with a wound $<1 \mathrm{~cm}$ long and clean

Type II: An open fracture with a laceration $>1 \mathrm{~cm}$ long without extensive soft tissue damage, flaps, or avulsion

Type III: Either an open segmental fracture, an open fracture with extensive soft tissue damage, or a traumatic amputation. Special categories in Type III were gunshot injuries, farm injuries, and open fractures requiring vascular repair.

The same team published another paper in 1984 on the problems in the management of Type III (severe) open fractures and introduced a new classification of Type III open fractures. ${ }^{3}$ They felt the need to subclassify Type III because of varied severity and prognosis and felt that the "current practice of having Type III is too inclusive." The paper was based on their experience in the management of 87 fractures in 75 patients during the period 1976 to 1979 . The classification 
which is presently widely followed thus came into existence. The essential features of the classification were as follows

Type IIIA: Adequate soft tissue coverage of a fractured bone despite extensive soft tissue laceration or flaps, or high energy trauma irrespective of the size of the wound.

Type IIIB: Extensive soft-tissue injury/loss with periosteal stripping and bone exposure. This is usually associated with massive contamination.

Type IIIC: Open fracture associated with arterial injury requiring repair.

Wound sepsis in the three subtypes were Type IIIA-4\%, IIIB-52\%, and IIIC-42\%; while amputation rates were 0,16 , and $42 \%$, respectively. Five patients in the series died, all as a result of multisystem trauma. In this article, the emphasis was mainly on the infection rates and to a certain extent on the need for soft tissue replacement. There was no special mention of different types of fractures. Ninety percent of the patients where soft tissue cover was provided were covered with skin grafts. That makes us infer that the study group did not have severe injuries which are now salvaged with flap cover, which makes it obvious that further refinements are needed in Grade IIIB. Gustilo used this classification for both upper and lower limbs.

The other popular score which is used is the Mangled Extremity Severity Score (MESS) score introduced by Johansen et al in $1990^{4}$ (- Table 1). MESS score was widely used and a score of 6 or less was considered compatible with salvage and a score of 7 or more usually ended up with amputation. Soon MESS score was found to be too far generalized with the scores being heavily weighted for vessel injury and ischemia. With the advent of microsurgery many limbs with vascular injuries who had high MESS scores could be saved. With developing experience, it was proved that a score of 7 could no longer kept as cut-off to decide on amputation. ${ }^{5}$

\section{Changing Paradigms in Limb Salvage}

The study of history of medicine would reveal that innovations and changes in practice force a change in strategy. Management of severe lower limb injury was no exception. The introduction of microsurgery, the concept of radical debridement, and the efforts of Godina in promoting the concept and safety of early soft tissue cover with free flaps was a game changer. ${ }^{6}$ Closer collaboration between the orthopaedic and plastic surgical teams and advances in anesthesia and monitoring techniques made long and staged procedures safer, radically changing the outcomes.

At the same time, social changes were also taking place bringing in changing perspectives on healthcare delivery forcing accountability in healthcare decisions. Cost of care, time away from work, and quality of life assessments were introduced into practice. While they helped in certain aspects, it also made decision making more complex in a condition like the salvage of a severely injured lower extremity. Surgical outcomes had also to compete with the progress made in the manufacture of prosthetic limbs. Outcomes of
Table 1 Mangled Extremity Severity Score

\begin{tabular}{|c|c|c|}
\hline \multicolumn{3}{|c|}{ Skeletal/Soft tissue group } \\
\hline Low energy & $\begin{array}{l}\text { Stab wounds, simple closed fractures, } \\
\text { small caliber gunshot wounds }\end{array}$ & 1 \\
\hline $\begin{array}{l}\text { Medium } \\
\text { energy }\end{array}$ & $\begin{array}{l}\text { Open or multiple level fracture, dislo- } \\
\text { cations, moderate crush injuries }\end{array}$ & 2 \\
\hline High energy & $\begin{array}{l}\text { Shotgun blast (close range) high- } \\
\text { velocity gunshot wounds }\end{array}$ & 3 \\
\hline $\begin{array}{l}\text { Massive } \\
\text { crush }\end{array}$ & Logging, rail road, oil rig accidents & 4 \\
\hline \multicolumn{3}{|l|}{ Shock group } \\
\hline $\begin{array}{l}\text { Normoten- } \\
\text { sive hemody- } \\
\text { namics }\end{array}$ & $\begin{array}{l}\text { Blood pressure stable in field and } \\
\text { operating room }\end{array}$ & 0 \\
\hline $\begin{array}{l}\text { Transiently } \\
\text { hypotensive }\end{array}$ & $\begin{array}{l}\text { Blood pressure unstable in field but } \\
\text { responsive to intravenous fluids }\end{array}$ & 1 \\
\hline $\begin{array}{l}\text { Prolonged } \\
\text { hypotensive }\end{array}$ & $\begin{array}{l}\text { Systolic blood pressure }<90 \mathrm{~mm} \mathrm{Hg} \\
\text { in field and responsive to intravenous } \\
\text { fluid only in operating room }\end{array}$ & 2 \\
\hline \multicolumn{3}{|l|}{$\begin{array}{l}\text { Ischemia } \\
\text { group }\end{array}$} \\
\hline None & $\begin{array}{l}\text { Pulsatile limb without signs of } \\
\text { ischemia }\end{array}$ & 0 \\
\hline Mild & $\begin{array}{l}\text { Diminished pulses without signs of } \\
\text { ischemia }\end{array}$ & 1 \\
\hline Moderate & $\begin{array}{l}\text { No pulse by Doppler, sluggish capillary } \\
\text { refill, paresthesia, diminished motor } \\
\text { activity }\end{array}$ & 2 \\
\hline Advanced & $\begin{array}{l}\text { Pulseless, cool, paralyzed, and numb } \\
\text { without capillary refill }\end{array}$ & 3 \\
\hline \multicolumn{3}{|l|}{ Age group } \\
\hline$<30$ years & & 0 \\
\hline $30-50$ years & & 1 \\
\hline$>50$ years & & 2 \\
\hline
\end{tabular}

If ischemia time $>6$ hours, add 2 points.

limb salvage were being compared with outcomes of early amputation with fitting of the best available prosthesis. ${ }^{7}$ Numerous scores were postulated to predict the feasibility/ usefulness of limb salvage (-Table 2 ).

A Lower Extremity Assessment Project study was undertaken at eight Level I trauma centers in the United States to assess the validity of the scores. ${ }^{12,13}$ The study did not validate any of the lower extremity severity scores. High specificity of the scores in all the patient subgroups did confirm that low scores could be used to predict limb salvage potential. But the converse was not true. Low sensitivity of the indices failed to support the validity of the scores as predictors of amputation.

Table 2 Scores to predict usefulness of limb salvage

Hanover Fracture Scale 97 (HFS 97, 1982)
Predictive Salvage Index (PSI, 1987)
Limb Salvage Index (LSI, 1991) $^{10}$
Nerve Injury, Ischemia, Soft Tissue injury, Skeletal injury,
Age (NISSA, 1994)


The problem was in the Type IIIB, which required further study, where decision to salvage or amputate was crucial. Either way, wrong decisions had serious consequences. There was a need for guidance to make the decision to salvage and also the sequence of what to do.

The Ganga Hospital Open Injury Severity Score (GHOISS) specifically addressed the challenges in decision making of Type IIIA and B open tibial fractures. ${ }^{14}$ To help in making the assessment more accurate, items which would have a bearing on outcome were provided incremental scores based on the severity of injury. Four factors were taken into account

1. Skin and soft tissues

2. Bone

3. Musculotendinous units

4. Comorbid factors which have a bearing on outcome

The first three items were scored from 1 to 5 based on incremental severity of injury, and for the fourth item, presence of each comorbid factor which definitely influenced the outcome was given 2 points ( - Table 3 ). GHOISS is specifically for open Grade III tibial fractures, where there is difficulty in decision making. The scoring is done at the end of debridement. A score of 14 and below is compatible with salvage, while with a score of above 17 primary amputation must be considered. This score also gives a gray zone of 15 and 16 wherein decision has to be made on a case-by-case basis based on the patient factors, surgeons' skills, and the available infrastructure. The GHOISS has been widely accepted in orthoplastic units. ${ }^{15}$

In addition to being useful for making the decision on salvage, the score can also be used as a guide to the sequence of management, and as to how far one can go on the reconstructive pathway on day $1.16,17$

\section{Utility of the Scores and Making the Decision between Salvage and Amputation}

An analysis of the evolution of the scores would reveal that each of them had tried to fill in the gap that existed in the previous one. Gustilo open injury score is followed extensively and for the problem of Grade IIIB open fractures of the leg, where decision making is crucial, the GHOISS is most applicable and is widely followed. For patients with injuries of high GHOISS scores, senior input is a must and in the borderline scores a serious thought must be given for referral to higher centers.

While the scores tell us the feasibility of salvage, practicality depends most on the skills and the attitude of the surgeon and the infrastructure he works in. Salvage versus amputation becomes a complex issue because the outcome is dependent upon three variables-the patient factors, the injury factors, and the surgeon factors ( - Fig. 2). While we don't have control over the patient and the injury factors, the only variable which makes a significant difference is the skills and the attitude of the treating team of surgeons and anesthesiologists, particularly when the scores are higher. At the end of resuscitation or at the end of debridement the treating surgeons must answer the question, "Can all the needs of this patient be met from start to finish?" If the answer is a clear "Yes," the patient could be
Table 3 Ganga Hospital Open Injury Severity Score

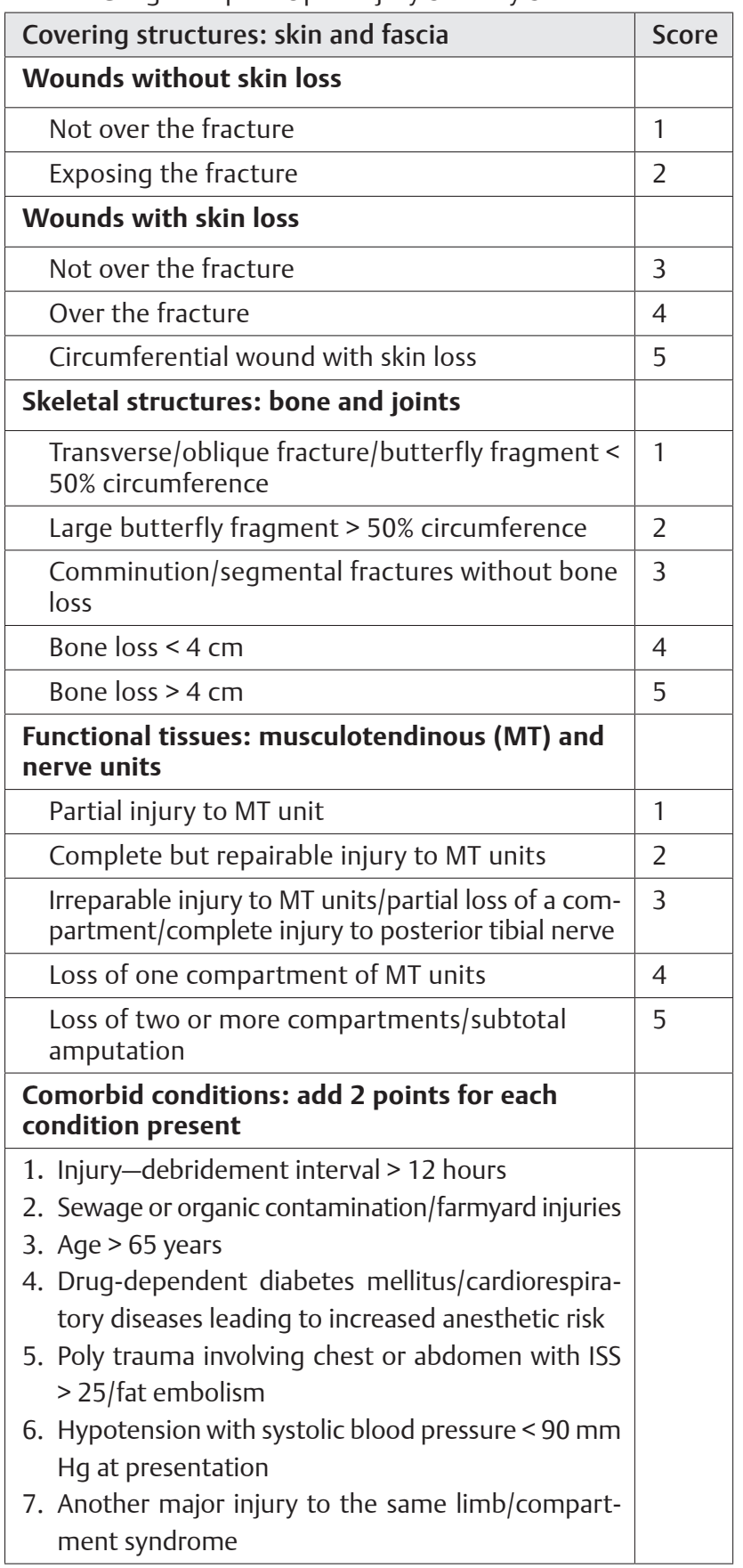

Abbreviation: ISS , Injury Severity Score.

retained and treated in the center. If the answer is "No," the patient must be referred to the center where the salvage might be possible. Patient transfers after complications have set in result in increased rates of morbidity, secondary amputation, and unacceptable increase in the cost of care. Most problems in the management of severely injured lower extremities occur due to infection. Infection is related to the quality of debridement and the timing of soft tissue cover.

\section{Initial Assessment}

A person with massively injured upper extremity could also have associated injuries. All patients must go through the 


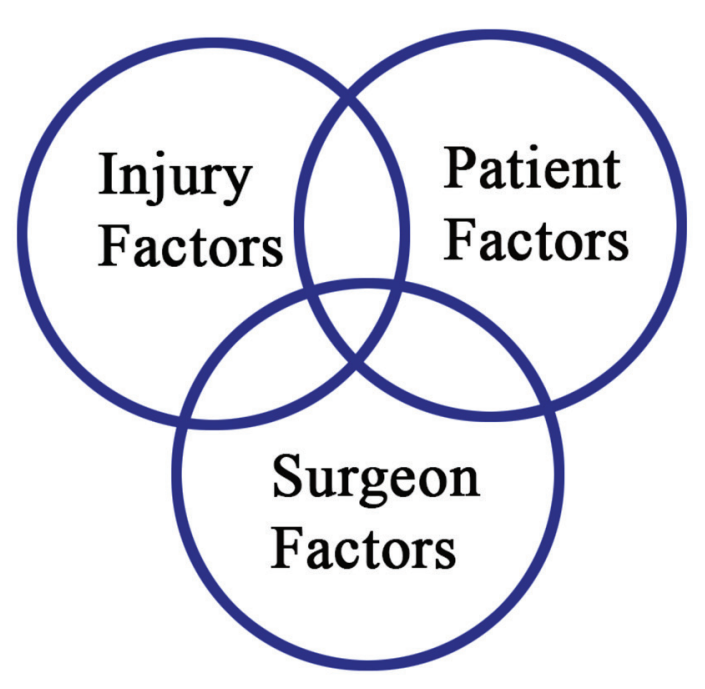

Fig. 2 Determinants of outcome in a severe injury.

Advanced Trauma Life Support (ATLS) protocol. Massively injured extremity is attention seeking, and hence we should not fall into the trap of falling for the obvious and missing a potentially life-threatening injury. At Ganga Hospital, we found that over a 6-month period, 110 patients with severe lower limb injury required massive resuscitation and intensive care management. In this group, 71 had multisystem involvement: head injury-31, faciomaxillary injury-19, chest injury-22, abdominal injury-16, upper extremity injury-17, spinal injury-7, pelvic injuries-23. During the same period, 520 open fractures of the lower limb were treated.

Once other injuries are ruled out, the first examination of the injured extremity is assessment of the vascular status. The dorsalis pedis and posterior tibial artery must be palpable. If they are not palpable in the injured limb when they are present in other limbs, it must be presumed that the patient has got a vascular injury and restoration of circulation becomes the priority.

The resuscitation goals are to keep the duration of hypoxia, hypotension, and hypothermia as low as possible. Splinting of femur fractures by application of Thomas splint and application of pelvic binders in case of associated pelvic fractures help in reducing blood loss.

It is best to have assessment done by a combination of senior plastic and orthopaedic surgeon along with an anesthesiologist who will be involved in the care of the particular patient. To make this happen as per the Ganga Hospital Protocol, all the massively injured patients are received in the anteroom of the operation theater. This provides them access to the anesthesia consultant who are primarily involved in resuscitation. If there is an actively bleeding wound, the attention is first directed towards the control of bleeding even before examining the patient as per the ATLS Protocol. In such cases, the application of direct compression bandage is the first response. This is followed by application of tourniquet proximal to the wound in cases of severe bleeding injuries below the knee. An unanesthetized limb can tolerate tourniquet for 20 minutes which is adequate time to get additional help. A quick examination is done for the sensation and peripheral nerve blockade can be given to reduce pain.

As assessment and resuscitation measures are in progress, $1.5 \mathrm{~g}$ of cefuroxime is given intravenously. Provision of antibiotic cover as early as possible significantly reduces the incidence of infection. ${ }^{18,19}$ In severely injured extremities, antibiotics are not prophylactic but considered therapeutic. Antibiotics are usually continued till wound closure.

Barring situations where the limb is extremely crushed with no chances of reconstruction, decision regarding amputation and the definitive scoring for salvage is done at the end of debridement.

The patient should be taken up for debridement as early as possible. Conventionally, it is said that debridement has to be done within 6 hours surgery.

The origin of the " 6 hour rule" is attributed to Friendrich (1898) who performed experimental tissue contamination studies in guinea pig soft tissue wounds, and observed that the effectiveness of debridement was limited if performed > 6 hours after injury. ${ }^{20}$ Robson et al took it further, when he reported that $10^{5}$ organisms per gram of tissue are needed to cause clinical infection. ${ }^{21}$ He said that this infection threshold was reached in an average time of 5.17 hours. Numerous attempts have been made to verify the authenticity of this idea. No study has been able to prove the significance of the injury-debridement interval. Due to the lack of conclusive evidence, some surgeons have gone on to emphasize the risk of early surgery in an unprepared patient by an inexperienced team or compromised infrastructure can do more harm to the patient. The British Orthopaedic Association/ British Association of Plastic Reconstructive and Aesthetic Surgeons guideline on the management of open fractures suggests that debridement be performed within 24 hours of injury on scheduled trauma lists, combining plastic and orthopaedic involvement where possible. ${ }^{22}$

While it is agreed that early surgery under compromised conditions is not good, it must not lead one to be complacent in taking up these patients for early debridement. Based on personal experiences of managing around 900 to 1000 open fractures of the lower limb at Ganga Hospital, we found that patient must be taken up for debridement as early as possible for the following reasons. First, in massively injured lower extremities, significant amount of blood loss may occur from large raw areas that may need blood transfusion. Hypotension and more blood transfusion are associated with increased incidence of complications. Second, severely injured patient do have pain, and taking them up for early surgery and stabilizing the fractures greatly helps to reduce pain related complications.

\section{Debridement}

Debridement is the key to success. The goal of debridement is to have a wound free of contaminants and ensure that all the tissues left in the wound are viable. Debridement has to be done under good anesthesia and tourniquet, with adequate lighting and magnification by experienced surgeons. It is 
good to have both the plastic and the orthopaedic surgeons together at the time of assessment and debridement. Presence of the orthopaedic surgeon would help in assessing bone of questionable viability, and in the choice of fracture fixation and placement of external fixators which facilitate the provision of soft tissue cover procedures. Involvement of the plastic surgeon gives confidence to radically debride the wound, the extent of excision of degloved skin, be aware of the tissues lost and tissues available for future reconstruction, the integrity of the vessels on which flaps could be based or the choice of recipient vessels be made for the free flap.

Tourniquet helps in better visualization of contaminants in between the tissue planes and helps make the discretion between viable and nonviable tissues. If the debridement is done without tourniquet, the bleeding that occurs on the excision of the skin margins covers the raw area and could masquerade the contaminants. Further when large areas are debrided without tourniquet, it will result in considerable loss of blood.

Skin margins are freshened by a sharp blade, and subcutaneous tissues are excised to reach bright yellow normal looking fat. Good muscles under tourniquet look pale and homogenous while nonviable muscles are heterogenous, and have small blood clots in them. Free bone fragments without any soft tissue cover are removed. Such cortical bone does not survive as bone grafts. Fractured bone ends are freshened with a Rongour if they are contaminated. Short segments of bone at fracture site bereft of periosteum can be expected to survive if they are covered by well-vascularized soft tissue cover before they dry up. Collagen sheets can be applied to keep the bone ends moist for $\sim 48$ to 72 hours $^{23}$.

Irrigation of the wound and the fluid for irrigation have been the subject of many studies. If the wound is grossly contaminated, we give a gentle wash with running water. No effort is made to use pressure irrigation as the primary step. This will drive contaminants into deeper planes. Low pressure irrigation is done at the end of surgical debridement. Presence of antibiotics in the irrigating fluids does not reduce the infection rates. It has been found that plain clean water is as good as any fluid. ${ }^{24}$ The thrust is on surgical debridement and flow of fluid than on the content or the pressure. ${ }^{25}$

Though the word "radical" is used to describe the quality of debridement, it is not en bloc excision of tissue as done during cancer clearance. Longitudinal structures like nerves and tendons in continuity and blood vessels must be preserved. Often, they are contaminated. A tissue plane exists over the neurovascular structures and excision of the tissues must be done in that plane preserving the integrity of the nerves and vessels. If this process is not done adequately, the inflammation and tissue edema that secondarily set in around the neurovascular structures cause fibrosis and make the vessels unavailable as recipient vessels for free flap cover.

When debridement is complete, the tourniquet is let down and the viability of skin margins is assessed by the presence of subdermal bleeding. The viability of muscles is assessed by its color and contractility. If there is doubt or nonviable structures exist, the tourniquet is inflated and debridement is done again. This is repeated until one is satisfied that all the tissues left are viable and free from contamination.
An essential part of patient care in the management of severely injured lower extremity is proper recording of the operative procedure. The extent of skin loss, the muscles and the tendons damaged, the tendons retained, the status of the nerves must be recorded in the operation notes. If there is a segmental loss of tendon, the proximal end must be anchored under stretch to the nearby soft tissues and the fact recorded in the notes. Similarly, the site of proximal and distal ends of the injured nerves are documented. This will help during secondary reconstruction by ease of access.

At the end of debridement, the team should decide if the skeletal fixation would need revision and in case the definitive fixation, the provisional timing and type of soft tissue cover must be made by the plastic surgeon. Early soft tissue cover is important and if future access is needed for secondary reconstruction, skin flaps are preferred. The type of flap used does not have a bearing on the rate of infection. Infection rate is related to the quality of debridement and the timing of soft tissue cover. The future plan must be made known to everyone in the team including the anesthesiologists. Communication is the key to success wherever teamwork is involved and senior team members should set the example for the entire team to follow. This would result in consistently obtaining good outcomes in major open fractures.

\section{Conclusion}

The goal of management of a severely injured lower extremity is to achieve painless, independent weight bearing walking in a time frame and cost that the patient can afford. This must be achieved without undue morbidity to the patient. The first surgeon who sees the patient holds the key to success. He must use the available limb salvage predicting scores, relate the available skills to the demands of the patient's injury, and decide on salvage versus amputation. Infection is the single most important complication which increases morbidity and cost of care. Debridement and provision of early soft tissue cover are crucial to prevent infection. Correct decisions and appropriate care provided on day 1 are the first steps which ensure success.

\section{Conflict of Interest}

None declared

\section{References}

1 Hughes CD, Tran BNN, Rinkinen J, Lee BT, Iorio ML. Readability, suitability, and complexity of online resources for lower extremity reconstruction. Ann Plast Surg 2019;82(1):2-6

2 Gustilo RB, Anderson JT. Prevention of infection in the treatment of one thousand and twenty-five open fractures of long bones: retrospective and prospective analyses. J Bone Joint Surg Am 1976;58(4):453-458

3 Gustilo RB, Mendoza RM, Williams DN. Problems in the management of type III (severe) open fractures: a new classification of type III open fractures. J Trauma 1984;24(8):742-746

4 Johansen K, Daines M, Howey T, Helfet D, Hansen ST Jr. Objective criteria accurately predict amputation following lower extremity trauma. J Trauma 1990;30(5):568-572, discussion 572-573 
5 Togawa S, Yamami N, Nakayama H, Mano Y, Ikegami K, Ozeki $\mathrm{S}$. The validity of the Mangled Extremity Severity Score in the assessment of upper limb injuries. J Bone Joint Surg $\mathrm{Br}$ 2005;87(11):1516-1519

6 Godina M. Early microsurgical reconstruction of complex trauma of the extremities. Plast Reconstr Surg 1986;78(3):285-292

7 Doukas WC, Hayda RA, Frisch HM, et al. The Military Extremity Trauma Amputation/Limb Salvage (METALS) study: outcomes of amputation versus limb salvage following major lower-extremity trauma. J Bone Joint Surg Am 2013;95(2):138-145

8 Tscherne $\mathrm{H}$, Oestern $\mathrm{HJ}$. [A new classification of soft-tissue damage in open and closed fractures (author's transl)]. Unfallheilkunde 1982;85(3):111-115

9 Howe HR Jr, Poole GV, Hansen KJ, et al. Salvage of lower extremities following combined orthopedic and vascular trauma. A predictive salvage index. Am Surg 1987;53(4):205-208

10 Russell WL, Sailors DM, Whittle TB, Fisher DF Jr, Burns RP. Limb salvage versus traumatic amputation. A decision based on a seven-part predictive index. Ann Surg 1991;213(5):473480 , discussion $480-481$

11 McNamara MG, Heckman JD, Corley FG. Severe open fractures of the lower extremity: a retrospective evaluation of the Mangled Extremity Severity Score (MESS) J Orthop Trauma 1994;8(2):81-87

12 Bosse MJ, MacKenzie EJ, Kellam JF, et al. A prospective evaluation of the clinical utility of the lower-extremity injury-severity scores. J Bone Joint Surg Am 2001;83-A(1):3-14

13 Bosse MJ, MacKenzie EJ, Kellam JF, et al. An analysis of outcomes of reconstruction or amputation after leg-threatening injuries. N Engl J Med 2002;347(24):1924-1931

14 Rajasekaran S, Naresh Babu J, Dheenadhayalan J, Shetty AP, Sundararajan SR, Kumar M. A score for predicting salvage and outcome in Gustilo type-IIIA and type-IIIB open tibial fractures. J Bone Joint Surg Br 2006;88(10):1351 -1360

15 Nanchahal J, Nayagam S, Khan U, Moran C, Barrett S, Sanderson F. Classification of open fractures. In: Standards for the Management of Open Fractures of the Lower Limb. British Association of Plastic Reconstructive and Aesthetic Surgeons. London: Royal Society of Medicine Press Ltd; 2009:24
16 Rajasekaran S, Sabapathy SR, Dheenadhayalan J, et al. Ganga Hospital Open Injury Score in management of open injuries. Eur J Trauma Emerg Surg 2015;41(1):3-15

17 Rajasekaran S, Sabapathy SR. A philosophy of care of open injuries based on the Ganga hospital score. Injury 2007;38(2):137-146

18 Hauser CJ, Adams CA Jr, Eachempati SR; Council of the Surgical Infection Society. Surgical Infection Society guideline: prophylactic antibiotic use in open fractures: an evidence-based guideline. Surg Infect (Larchmt) 2006;7(4):379-405

19 Chang Y, Kennedy SA, Bhandari M, et al. Effects of antibiotic prophylaxis in patients with open fracture of the extremities: a systematic review of randomized controlled trials. JBJS Rev 2015;3(6):01874474-201503060-00002

20 Crowley DJ, Kanakaris NK, Giannoudis PV. Debridement and wound closure of open fractures: the impact of the time factor on infection rates. Injury 2007;38(8):879-889

21 Robson MC, Duke WF, Krizek TJ. Rapid bacterial screening in the treatment of civilian wounds. J Surg Res 1973;14(5):426-430

22 Nanchahal J, Nayagam S, Khan U, Moran C, Barrett S, Sanderson F. Timing of Wound Excision in Open Fracture. In: Standards for the Management of Open Fractures of the Lower Limb. British Association of Plastic Reconstructive and Aesthetic Surgeons. London: Royal Society of Medicine Press Ltd; 2009:11-12

23 Venkatramani H, Sabapathy SR. Collagen sheets as temporary wound cover in major open fractures before definitive flap cover. Plast Reconstr Surg 2002;110(6):1613-1614

24 Fernandez R, Griffiths R. Water for wound cleansing. Cochrane Database Syst Rev 2012;2(2):CD003861

25 Petrisor B, Sun X, Bhandari M, et al; FLOW Investigators. Fluid lavage of open wounds (FLOW): a multicenter, blinded, factorial pilot trial comparing alternative irrigating solutions and pressures in patients with open fractures. J Trauma 2011;71(3):596-606 